\title{
On the diffusion of software technologies: technological frameworks and adoption pro- files ${ }^{1}$
}

\author{
G. León \\ Dep. of Telematics Engineering \\ Universidad Politécnica de Madrid \\ Ciudad Universitaria 28040-Madrid (Spain) \\ Ph: +3413367334 \\ Fax: +3413367333 \\ E-mail: gleon@dit.upm.es
}

\begin{abstract}
This paper presents an analysis of the forces that constrain the diffusion of software technologies in the organizations from the perspective of the technological frameworks exhibited by individuals and the social groups to which they belong.

In the adoption process, stakeholders are organized as circles of diffusion; each group possesses different reference frameworks that constrain the way that information technology is accepted and diffused. These constraints are explained in terms of the lack of congruence between the technological frameworks exhibited by the different groups.

After characterizing the transition groups in terms of the adoption profiles we postulate a set of actions to decrease the risks of failure in the adoption of software technologies. Finally, the ideas are applied to the analysis of a technology transfer case with FDTs in the telecommunication domain.
\end{abstract}

\section{Keywords}

Technology transfer, Technological frames, Software technologies, Formal methods, Adoption profiles

\footnotetext{
${ }^{1}$ This work has been partly sponsored by the Spanish Research Council under project EMEDAS
} 


\section{INTRODUCTION}

It is well known that the introduction of a new technology in one organization not always produces the intended benefits (Levine, 1994). In many cases, either the receivers do not reach the intended level of use or simply the technology is rejected because it does not match with the expectations (true or false) and the accepted psychological effort to use it. The case of formal methods is a paradigmatic example of continual failures.

The published cases with problems or failures only constitute the visible part of a large iceberg of adoption cases. It is difficult to get companies to openly express the problems they had; however, from the experience of the author, failure cases are very common and they include any type of company. Many reasons to explain the failures (and in some cases the successes) could be postulated; however, the experiences are not structured enough and it is difficult to extract from them useful guidelines for avoiding future problems.

Generally speaking, there is a trend to find the root of the problems in the technology itself and in its adequacy with the preexistent technological context. Technocratic technology transfer models describe the problems in terms of these aspects. Although it is true that those factors limit the probability of success, there is another source of explanations linked to the individuals and working teams and how they perceive the technology.

Before entering into the analysis of the problem, the concept of software technology as used in this paper ${ }^{2}$ will be presented.

Software technology is understood as a set of integrated notations, tools and methods, based on sound principles to develop and maintain a software product in a given organizational context.

A software technology is composed of the following elements (see figure 1): a set of textual or graphical notations (semantically related); a reasoning framework to analyze the notations and to validate properties; a set of tools (more or less integrated) to support the notations and the reasoning framework; methods for developing large systems by using the notations, tools and reasoning framework and industrial guidelines where the know-how in one application domain is structured (in (León et al., 1994) a more detailed definition of these concepts can be found).

When we address technology transfer and diffusion (technology diffusion is the process of making available a mature technology in a community of users and technology transfer refers to the process of inserting a technology into an organization that adopts and probably adapts it), the technology cannot be considered in an isolated way if we wish to understand the associated problems. Following the above mentioned concepts, figure 1 depicts the relationships between technological components and the adoption context.

We postulate that the adoption success depends on the way that the components of the technology interacts with the adoption context. This interaction is strongly de-

\footnotetext{
${ }^{2}$ Although the reference is on software technology, most ideas and concepts can be applied to any type of information technology.
} 


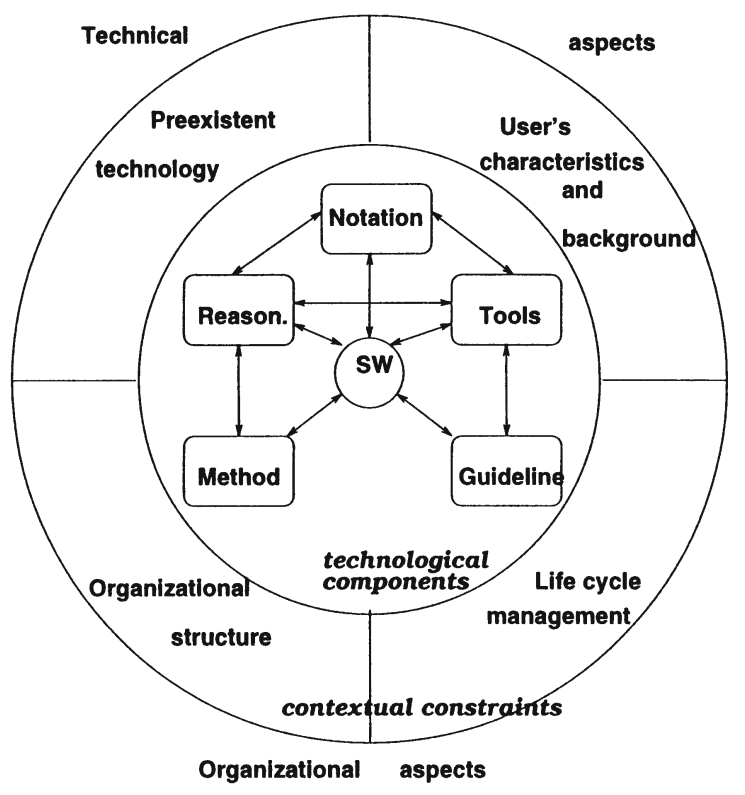

Figura 1: Technological components and adoption framework

pendent on the technological frameworks exhibited by people (individuals and groups) involved in the process.

The rest of the paper is organized as follows: section 2 presents the idea of technological frameworks and how it affects the perceived technology. Section 3 describes the concept of technology transfer profile and its relation with technological frameworks. Section 4 will present the idea of circles of technology diffusion where the identified stakeholders enter into contact. Based on those concepts, section 5 will describe an integrated model to speed up the diffusion of software technologies. In section 6 the model is applied to understand the diffusion problems found in one case study concerning the adoption of formal methods in the the telecommunication sector. Finally, from this experience some conclusions are summarized in section 7 .

\section{TECHNOLOGICAL FRAMEWORKS}

Reference frameworks are defined in cognitive psychology field as predefined structures of mental patterns that facilitate any experience or conduct. Reality is valued or interpreted with reference to these patterns.

Although the definition applies to individuals, it is possible to extend it to large social groups when they are composed by individuals sharing some relevant aspects concerning the reference framework. Orlikowski and Gash (1994) borrowed this idea to define the 


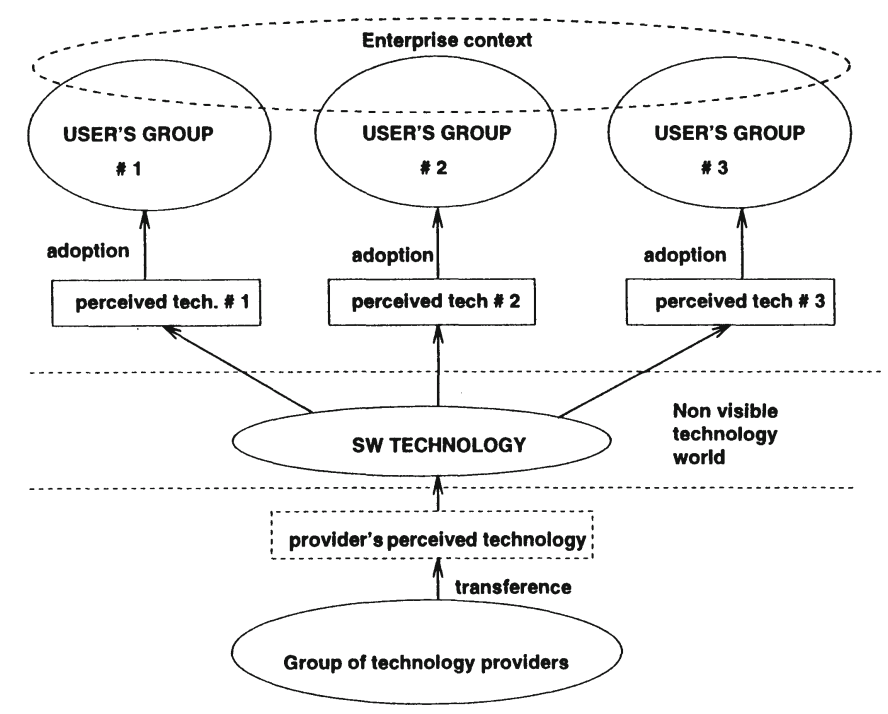

Figura 2: How the technology is perceived

technological frameworks as a subset of cognitive elements related with the technology (in their case, groupware technology).

In the above mentioned article, both authors establish the hypothesis that the inconsistency of technological frameworks (ambiguous, incomplete or incorrect concepts) is responsible for the reported problems of introducing a predetermined technology in a given industrial context. It explains why technology produces such a different reaction among people involved in different organizations even when the differences between current and target technology were the same in all of those organizations.

It is interesting to mention that when a technology is adopted by a community of users, they do not see the technology "as is" but as perceived technology.

A technology is the result of the description of its technological components and its relationships. Nevertheless, each receiver has a different lens that modifies this real technology in some of its specific components or inter-relationships as a function of its reference framework. Figure 2 expresses this idea. It also suggests that many people can share the same perceived technology although they were completely isolated (the idea of social group does not mean that they are working together; when it occurs, it will be termed a team) or different perceived technologies even when they belong to the same company (the case represented in figure 2).

Differences in observable behaviour of two communities with respect to the same technology are associated to the way that the perceived technology is evaluated (interpreted) in relation with a preexistent technological framework. In other words, the actual technology is filtered and perceived under a limited scope. 
Obviously, it is not a static process. The (new or old) inter-relations among individuals, the use of the technology and the modifications of the perceived technology are inputs for modifying the technological framework and, hence, the observable behaviour. Notice that providers also manage a perceived technology. This fact is even more important when the target technology is not completely stable. In this case, not only perceptions change with time; the technology itself is also a moving target.

The consequence of this analysis is that the adoption of a technology cannot be isolated from the adoption context and this fact avoids speaking of any technology in its pure form.

\section{ADOPTION PROFILES}

In order to assess the barriers for the adoption, we intend to identify a small number of features that globally permits us to understand the inherent difficulties of technology transfer and to serve as a comparison grid to evaluate a given adoption case with respect to well documented reference cases. The value of these features, define the so-called adoption profile.

Features were chosen to capture the most important aspects related with the technological framework. They come from three main sources:

- From the people involved, taking into account the freedom and reactions they have with respect to the technology transfer project. We assume that one of the main criteria to understand the difficulties of one specific technology transfer case comes from knowledge of the people's attitude and profile involved in the process.

- From the technology transfer context, to measure the way that the transference is carried out. Even with very motivated and free people, transference is constrained by the conditions associated with the adoption process itself.

- From the technology to be transferred. Here, the main aspects of the technology that affects the adoption (although we are not interested in the technology in itself) are considered.

The following subsections will present the chosen features.

A more general process to assess the innovative climate has been proposed (Bergman and Ohlund, 1995). They consider variables such as: challenge, freedom, idea-support, trust, dynamism, playfulness, debates, conflicts, risk-taking and idea-time to characterize an organization as innovative or stagnant. Globally, those aspects indicate the organization's attitude. We will follow in this paper a different approach in which the three different views are combined. 


\subsection{Receptor's attitude}

This takes into account the attitude of receptors during the adoption. Although it is true that in every case, many user's profiles participate in the process (from top management to administrative support), we prefer to take a global view of the receptor's value. The value to be included in the adoption profile is an average of the situation at the company level.

Three main cases are relevant:

- Passive. Organizations receive the new technology as an order taken outside them. In fact, decision about the technology to adopt, when, and where is taken outside them. This lack of motivation has been reported as a main barrier to a successful end of the transference (Fowler and Levine, 1993).

- Active. Receptors envision technology transfer process as a necessary personal decision. They assume the responsibility for choosing the technology and how it is used. It is usually adopted for mature technologies.

- Cooperative. Receptors cooperate with providers in the design of the technology transfer case. In this way, technology is adapted to the internal requirements at the company. We postulate that cooperative transferences are more suitable to cope with technology transfer of immature technologies by increasing the success probability.

\subsection{Formality of the adoption process}

This feature is intended to measure the degree of formalization in the process. If technology transfer is considered as a project, we are interested in knowing if a model is or is not used and if it is adjustable to the specific needs of the case. Three main points are relevant:

- Informal. Technology transfer is not a project. Activities are invented for receptors during the adoption. It relies on a naive view of the adoption process and is responsible for many of the reported failures.

- Planned. The project is conceived as a sequence of defined steps (phases and activities) following a predefined model.

- Progressive. Technology transfer project is conceived under a progressive model adapted to the evaluation of the technology transferred.

Notice that it is a complementary perspective of the receptor's attitude. We postulate that a progressive transference model is better adapted to cope with the problems behind the adoption of complex technologies. Probably, it is also a signal about the maturity of the processes at the company according to any model like CMM. Recently reported problems in accepting CMM from the receivers' standpoint (Saneidian, Kuzaro, 1995) can be also interpreted under those premises. 


\subsection{Interdependency of receptors and providers}

This perspective measures the relation between receptors and providers completing the view obtained from the above coordinates. Three main cases could be mentioned.

- Independent. Receptors act by themselves as a completely independent unit. They can freely decide on the technology to use and how it should be transferred.

- Subsidiary. They depend on the technology providers and probably the technology cannot be changed; however, they can decide about how the technology should be transferred and when.

- Chained. Receptors are strongly linked to the decision of providers. They should accept the new technology without further discussion. Technology transfer process is decided by providers.

\subsection{Pressures to start the technology transfer process}

Pressures are defined as any aspect that forces the adoption of a new technology. Although pressures have many sources (internal and external pressures to initiate the technology transfer project) we have preferred to collapse them into a single perspective to pick up the feeling on the process as a whole.

In other words, if receptors start the process because they cannot wait any longer, we will say that they are receiving huge pressures. Three cases are relevant:

- No pressures. If TT process starts it is because they would like to do so. I do not think that this naive situation can be found in practice; even innovative companies use very advanced technologies as a part of their role.

- Moderate pressures. Probably, receptors should start a technology transfer process although it is not mandatory to start now. They can accommodate the adoption pace to the severity of the problems.

- High pressures. TT should inevitably start ... and soon, before competitivity decreases under a predefined threshold.

\subsection{Impact of the technology}

Impact measures the effect of the technology in case of adoption on the user's organization and working procedures. Large impact technology means that many things should be changed to take advantage of the potential benefits offered by the technology under adoption. Three situations are representative: 
- Low. Technology only affects specific individuals in one of the development activities (included in one phase of the life cycle) and it could be mastered in a short time.

- Moderate. Technology affects a working team during a phase of the development life cycle and it takes weeks to months to be mastered.

- High. Technology affects the whole project team, several phases of the development are affected and it takes months to years to be mastered.

\subsection{Maturity}

Maturity is a measure of the effort required to use the technology for its main purpose. Mature technologies also means that they have reached a stable situation where providers have experience, transference material and know how to help receptors during the adoption process. Three cases could be considered:

- Stable. Technology was developed some time ago and nowadays it is stable and well known.

- Progressing. Although the technology was developed some time ago, it is undergoing improvements (some components were not completely mature) or usability in one application domain is not yet assessed.

- Unstable. The technology is very immature and its transference will need cooperation between providers and receptors. This is a high risk situation.

Maturity is one of the basic parameters considered by organizations where risk is a basic factor for decision-making.

\subsection{Adaptability}

It measures the capability of the technology to be customized to the user's requirements. In principle, a customizable technology allows an easier integration into the user's environment.

- Fixed. Technology is used on an "as is" basis. Receptors cannot modify any of its components; then, technology transfer is devoted to master its use.

- Customizable. Several elements of the technology could be changed to accommodate them to the user's requirements or to the application domain.

- Open. Technology is not completely defined and it needs to be completed (defined) by the user. 


\subsection{Distance with respect to the current technology}

This coordinate measures the differences between source and target technology. We would not like to enter in this paper on the metrics associated with the distance, but it is easy to identify relevant aspects of the technology and to concentrate the effort on them. The effort required to complete the transference depends on the distance to be covered.

- Short distance. No specific problems should appear. Target technology could be considered as an improvement of the current one and technology transfer can be embedded in continuous process improvement activities.

- Medium distance. Some components of the current technology significantly change while others remain in use. This is the typical case of technology transfer within information technology because there are not many new software technologies available that remove all components of the old one. Medium distance advises the convenience of using a planned process.

- Large distance. This is the most problematic case because the differences between source and target technologies are so large than the probability of failure is very high. Probably, it is necessary to use another technology (to a shorter distance) as an intermediate step.

\subsection{Graphical representation of the adoption profile}

Although we have tried to describe them as separate views, it is common to find in practice some interdependences among them in order to ensure a successful project. Figure 3 summarizes most probable relations found in practice. Notice that two clusters clearly appear: one of them related with the technology and another one related with the context. The gap between both clusters reveals that the barriers against the adoption of a technology could be separately analyzed.

In order to obtain a global view of the technology transfer situation, we have depicted the coordinates in the diagram represented in figure 4.

The area covered by each profile is a sign of the difficulties and simplicity or complexity of the technology transfer considered. In figure 4, as a wider area is covered the situation is improved. Thus, it allows people involved to focus the attention on specific aspects where risk of problems are more probable just looking at the profile's shape.

We have used interdependencies between coordinates in the table to distribute them along the circumference. In this way, when the interdependence is high they are placed closer. As a consequence, profiles can be easily understood at a first glance.

\section{CIRCLES OF DIFFUSION}

In software development companies, more than isolated individuals, technologies are transferred to teams composed of people cooperating to perform a global activity (then, 


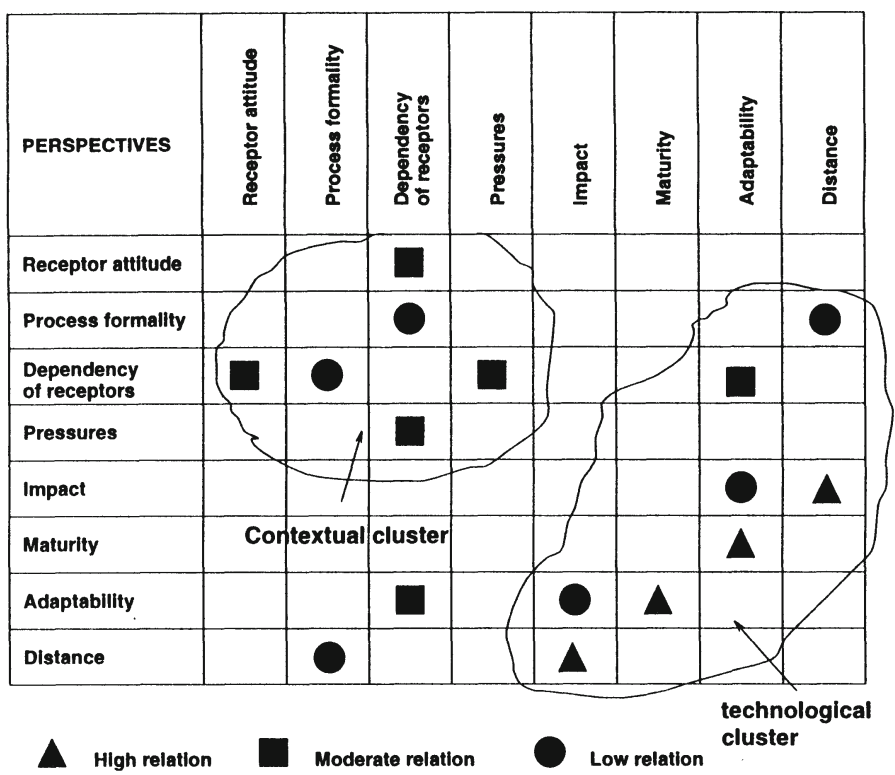

Figura 3: Dependencies between coordinates

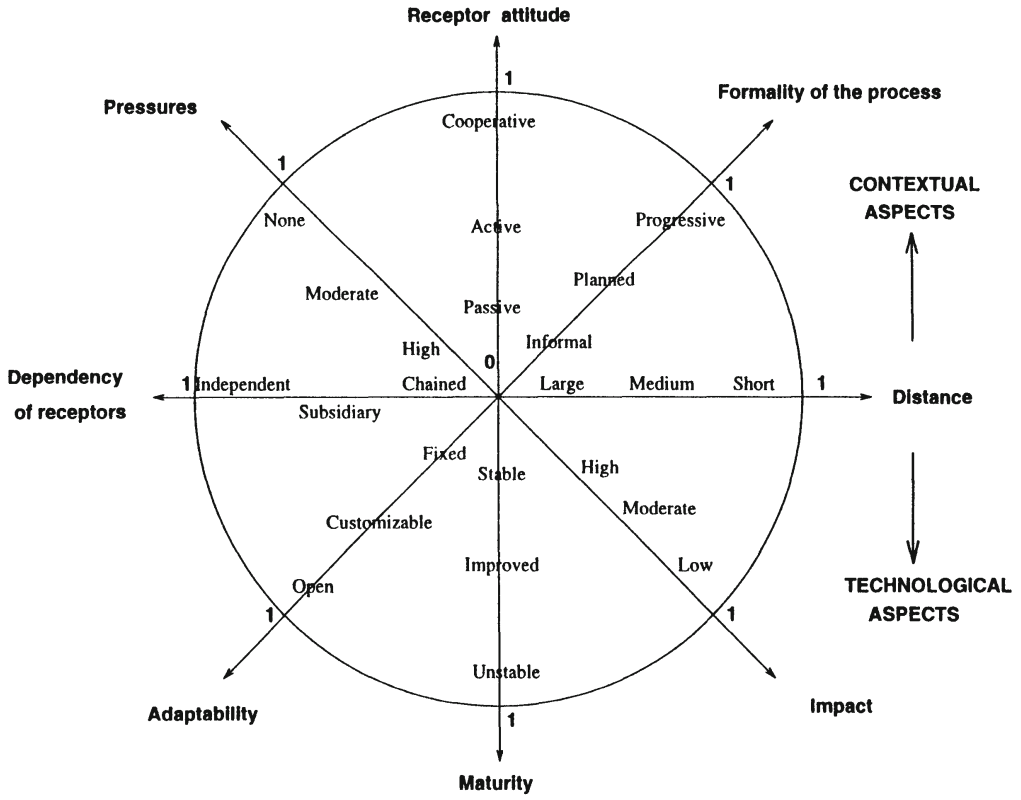

Figura 4: Graphical representation of TT profiles 
impact is, at least, moderate). In some cases, they use the same set of tools (conceptual or machinery-based); in others, they perform different tasks with a specific set of tools. As a consequence, the view of the technology is not the same.

When top management decides to start a technology transfer process, several groups related with this process are created. We postulate that the way that these groups interact during the adoption process significantly affects the success or failure of the process as a whole. For us, the company as a whole should be involved in the adoption process as the only way to increase the probability of success. This idea was also expressed by Shuster (1994) under the concept of "mobilizing the whole company".

\subsection{Identification of stakeholders}

In order to put in practice the circles of diffusion, the following stakeholders were identified:

- Top management. They constitute the reduced management core defining the strategy to adopt the technology. More than to evaluate or to define the transition process, this group is focused on maintaining the support for the entire process. It is common that top management makes an initial decision to stimulate the transition. Then, a top down approach to technology diffusion as the most common case found in practice. Only SME's can rely on a more bottom up approach due to their flattened structure.

- Transition group. It constitutes the group of people with the basic responsibility of selecting, evaluating and adopting the technology. It is composed of a group of people coming from the different areas of the company that cooperate in the diffusion of the technology as its main role. Providers could also participate when immaturity or adaptability becomes crucial.

- Pilot project development groups. In most cases, adoption of a new technology implies the development of some pilot products to test the adequacy of the technology to the typical products developed in the company. Development teams receive the technology from the transition group which incorporates some of its members in the development of pilot cases.

- Dissemination groups. Initially passive, these groups are the basis for the diffusion of the technology to the rest of the company. They periodically receive some information about the experiments (pilot cases), the technology and its potential advantages and disadvantages and offer feedback to the pilot and transition groups.

- Entreprise staff. The rest of the technical staff at the company. They appear when a decision about the technology has been adopted but they will be affected by it. 


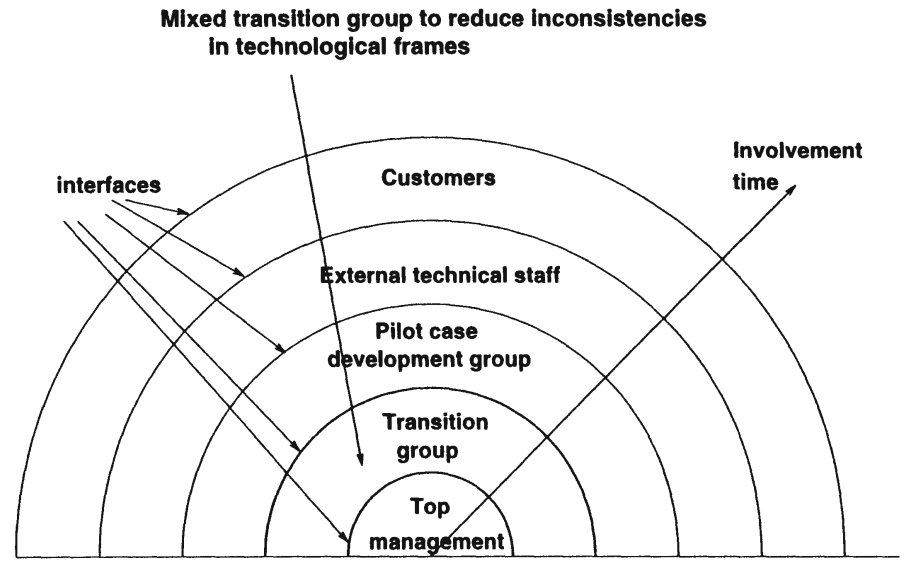

Figura 5: Circles of diffusion

- External customers. They are the receivers of the products developed with the new technology. Customers can belong to the same company or to others. In all cases, they should understand the effort made by their providers to adopt a new technology as a long-term benefit for them. Links should be enforced through marketing departments.

At each level, several profiles (project managers, developers, implementers, etc.) from the company and academia populate these groups. Figure 5 details the relation among people working at different circles of diffusion.

Interfaces between the different stakeholders as suggested in figure 5 are also filters of the technology. Each stakeholder possesses a technological framework generating different perceived technology. It explains the difficulties found traversing the interface (i.e., explaining the goals and roles with respect to the adoption process and the difficulties in interpreting the results). Figure 6 depicts this idea where two types of interfaces are shown. External interface between adjacent levels and internal interfaces within the components of the group.

From the discussion presented in this section, we postulate that the lack of congruence between technological frameworks used within the organization is primarily responsible for provoking the difficulties in the technological innovation process. Nevertheless, in spite of the creation of diffusion circles, the lack of common reference frameworks impedes the smooth exchange of information and, more importantly, the assessment of the technology and its impact is undermined. 


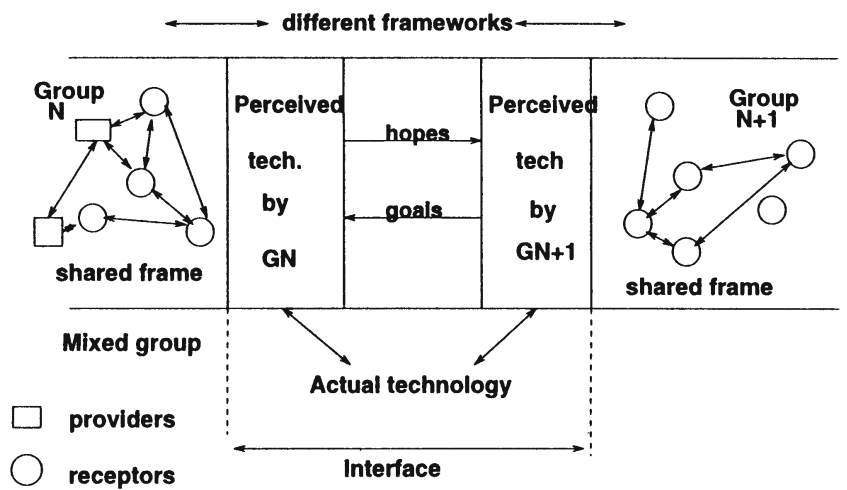

Figura 6: Perceived technology through the circles of diffusion

\subsection{Integrating concepts on diffusion of software technologies}

Until now, we have developed the concept of adoption profile as a mechanism for facilitating the global understanding of the adoption problems. Furthermore, the structure of circles of diffusion offers a layout to organize the process facilitating the interaction between people with different profiles and responsibilities. Interfaces have been presented as filters when technological frames between adjacent groups are very different. Now, all these concepts will be integrated to speed up the adoption of a new technology.

Time required to diffuse a technology in a company is strongly dependent on the mechanisms used by stakeholders to perform their work and to communicate information with other stakeholders through the defined interfaces. If both receivers and providers do not share the same framework, two possible positions could be held by people involved: to devote much more time to set it up or to ignore the differences; in this last case, the consequence is that the potential benefits are not realized.

The next table reflects the common elements of technological frameworks and the relation with the stakeholders defined above (the number of stars means the relative importance of the common element).

Columns reflect the stakeholders and rows the technological elements (in terms of the technology and its context) that constitute the technological frameworks in terms of expectations of the perceived technology. Items were extracted from the author's experience as the most important in technology transfer projects (other factors were found by Akao (1990) and Linton et al. (1992)). 


\begin{tabular}{|l|c|c|c|c|c|}
\hline \hline Element & Top manager & Transition & Pilot & Staff & Customer \\
\hline Motivation & +++ & +++ & ++ & + & \\
Responsibility & ++ & ++ & + & & \\
Background & + & +++ & ++ & ++ & + \\
Cost & +++ & + & & & ++ \\
Competitiveness & +++ & +++ & + & + & + \\
External image & + & ++ & + & + & ++ \\
Full use & & ++ & ++ & ++ & \\
Range of products & +++ & +++ & + & + & ++ \\
Resources & + & ++ & ++ & + & + \\
Effort & & ++ & +++ & ++ & +++ \\
Adoption time & ++ & +++ & ++ & ++ & \\
\hline Total values & 19 & 26 & 17 & 13 & 12 \\
\hline \hline
\end{tabular}

The analysis of the table reflects several important facts:

- Motivation and responsibility decreases from inner to outer circles. The consequence is that only a reduced group of people considers the adoption process as a problem. In fact, the use of top down approach always makes difficult the involvement of lower levels (outer circles). Specific measures to increase consciousness of it should be created.

- Several aspects that managers consider important to evaluate the success or failure of the process are not considered relevant for customers or staff. The consequence is that decision making is not understood by outer levels that perceive an erratic behaviour in its management staff. Information on goals and progress should be available to the whole company.

- Initial perception of problems is different. Thus, expectations are also different. Customers only perceive visible aspects of the technology although internal staff are worried about how the technology is adopted. The use of QFD techniques (Akao, 1990) can help in the creation of a common understanding.

The knowledge of the differences in technological frameworks and their impact on the adoption process is the basis for setting up policies to reduce them. They should be enforced in the management of the transition.

\section{EXPERIENCES FROM A CASE STUDY}

Following the ideas expressed above, we can try to understand the problems found in technology transfer when two different institutions with very different frameworks interact in the transference of an immature technology: a department at the University as 


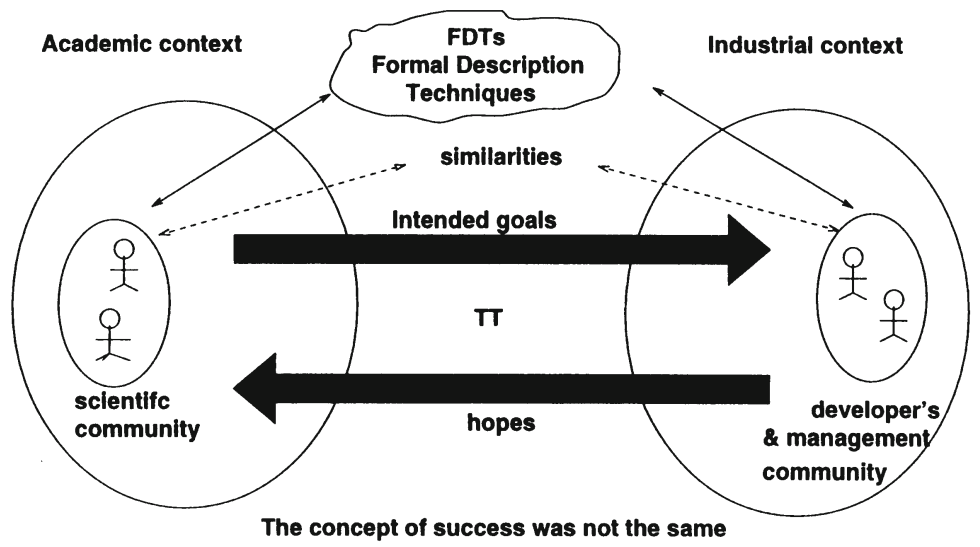

Figura 7: Scenario of FDT technology transfer

provider of a new technology based on formal methods and an industrial development group belonging to a large company adopting the technology provided by the university department. Technical aspects of this project have been recently reported ((León et al., 1994), (Yelmo et al., 1994)) and they will not be considered here.

We only mention that the involved technologies were LOTOS and SDL for the description of communication systems. The project spent three years under a controlled scenario. Figure 7 depicts the general framework of this experience.

Our experience relied on two basic assumptions: the technology was not mature enough to avoid feedback from providers; thus, an incremental model was used (León et a., 1994). On the other hand, to close up providers and receptors, a mixed transition group was created (both groups had similar technical background).

First of all, we will extrapolate several characteristics of the diffusion of new technologies in academic and industrial environments. Then, a preliminary analysis of technological frames and adoption profile will be summarized. Finally, some conclusions are presented.

\subsection{Diffusion in academic environments}

Academic environments are very complex social structures where faculty members perform very different tasks. We focus our attention on the R\&D activity. It is usually characterized by a very free and poorly organized scenario. Professors have a large influence on the activities carried out in the departments by other people working there. In this sense, professors act as supporters of a new technology usually linked to their own professional careers. $\mathrm{PhD}$ or master students are more focused upon technical work with little or no motivation for technology transfer. In fact, they do not know industrial wants and needs except when they are filtered by their supervisors. 
Typical problems found in this case concerning technological frameworks are:

- The use of the new technology does not appear as a consequence of problems in the development capability. The reasons are related with the publication of papers in congresses or journals or with $\mathrm{PhD}$ thesis related with the new technology.

- Costs are secondary. The use of a new technology is made because it has high potential to be developed, good research image or other causes.

- Poor understanding of industrial needs and wants. In some cases, the problem to be solved is idealized addressing symptoms and not causes.

- No motivation for diffusion except in professors when it is linked to funding research activities.

\subsection{Diffusion in industrial environments: software develop- ment companies}

Industrial environments are characterized by the adoption of new technologies in a top down manner triggered by losses of competitivity or by strategic objectives to increase user's satisfaction. In software development, failures in the introduction of formal methods are very well known and to reduce them was the basis of the commented case study.

Typical problems concerning technological frameworks in this case are:

- Software engineers on the receptor accept a top down approach and they feel that decisions are very far from their daily activity. Motivation is not evident.

The consequence is that formal methods should be adopted through systematic planning of the adoption process because it cannot rely on the motivation of people. Motivation must be explicitly created.

- Managers trigger the process with a very limited knowledge of the technology involved. They trust in the experience of other companies in the same field or in academic or industrial champions.

This situation forces us to consider managers as a very important target in the activity of transition groups. Obviously, they play a key role in the motivation of people.

- Technology is not only evaluated with respect to its technical soundness. For instance, verification capabilities of formal methods are not fully exploited in industrial practices. Main factor relies on its applicability and friendliness.

- The dynamics of the enterprise is based on the development of projects. Thus, people involved overvalue pilot cases and demos, and undervalue evaluation activities. It is related with the lack of clear rewarding mechanisms. This situation becomes crucial in project-driven organizations. 


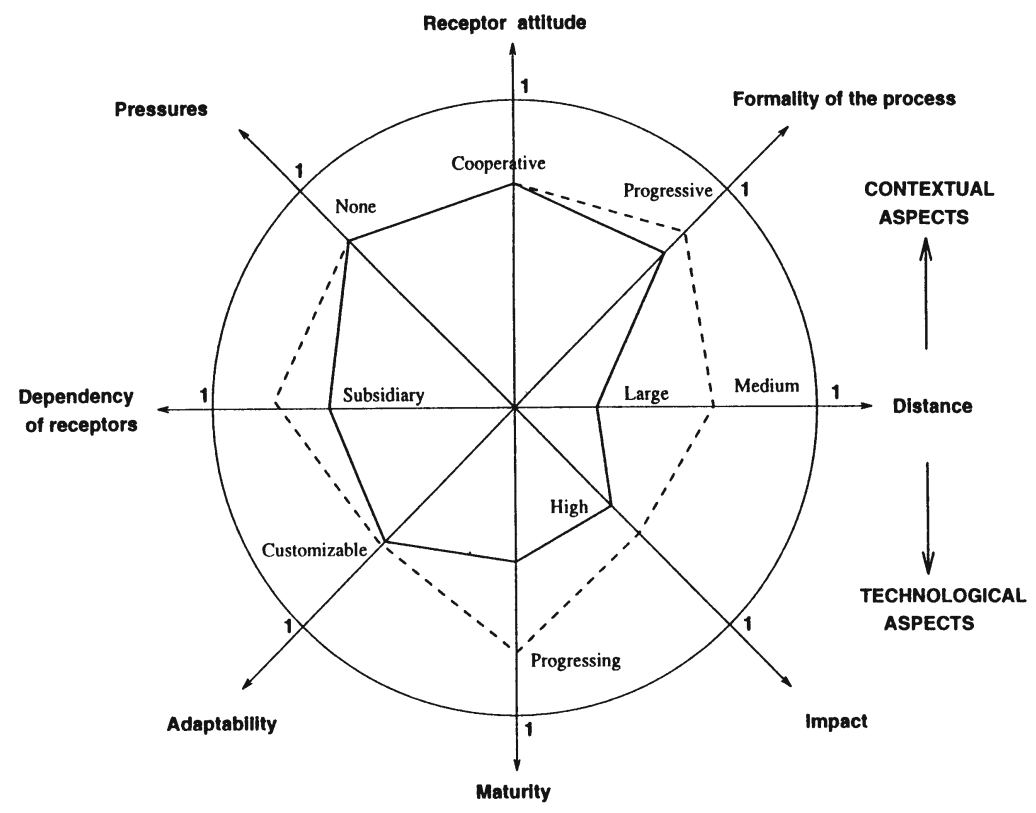

Figura 8: Adoption profile of FDT technology transfer case

\subsection{Analysis of the adoption profile}

It is interesting to compare the different contexts for adopting the same technology found in both cases. It is also interesting to comment that the background (telecommunication engineering) in both cases was practically the same.

The transference was done by creating a joint effort where circles of diffusion were composed of people belonging to both institutions. Figure 8 depicts the adoption profile of this case. SDL and LOTOS were considered separately.

A short rationale behind the coordinates follows:

- Receptor attitude. It is considered cooperative. Both providers and receptors participate in the transition group to transfer the technology.

- Process formality. An incremental multicycle model was used to adopt and to adapt the technology to the company's requirements.

- Dependency of receptors. During the first phase, receptors were subsidiary to providers. This role changed in the last stages of the adoption when knowledge of the technology was very similar between providers and receptors. With SDL no dependency appeared. In some sense, the borderline between providers and receptors was transparent. 
- Pressures. This was a rather free experiment in the sense that no deadline to adopt the technology was required. In fact. evaluation could be positive or negative; then, progressive commitment strategy was followed. The industry participated with a horizontal division where exploratory actions could be carried out as a part of its mission.

- Impact. Formal description techniques have high impact on the development life cycle. They take months (or years) to be mastered and they affect development projects as a whole.

- Maturity. Although the theoretical basis for LOTOS and SDL was known before starting the transference project (notation is a standard, prototypes tools were available and the capabilities of the reasoning framework have been extensively published), no industrial experience was available nor the applicability to large communication systems properly assessed. In this case, FDTs were in a progressing stage. Maturity degree of LOTOS and SDL is not the same (LOTOS is clearly less mature and provided by the academic group).

- Adaptability. FDT can be adopted in many ways. In this case, links with preexistent software development technologies were considered crucial. Then, customization of the technology was a very important goal.

- Distance. The industrial partner was using SDL (although automatic code generation was not used). Good implementation support and project management was available. LOTOS was not used at all.

The analysis of the shape exhibited by the profile indicates a good case for technology transfer with high probabilities of success. No special problems were anticipated except those derived from the technology itself (i.e. impact and distance). Risks with LOTOS were clearly higher than with SDL.

\subsection{The analysis of technological frameworks}

In spite of the relatively good adoption profile presented in the above section, the technological frameworks were not the same. This situation offers a complementary perspective to interpret the difficulties found.

Figure 9 summarizes the different perceptions of both institutions on FDT (Formal description techniques) and the role they played during the adoption process.

These incongruities made it difficult to obtain a common view of the degree of success or failure. As an example of the problems in the interfaces, the transition group (a mixed working group) needs to dialogue with top management (from the industry). Their motivations were very different and the concept of success was also different.

To the transition group, FDTs is a valuable technology to gain confidence in the quality of software products based on the powerful reasoning framework. Top management 


\begin{tabular}{|l|l|}
\hline \multicolumn{1}{|c|}{ ACEDEMIC GROUP } & INDUSTRIAL GROUP \\
\hline $\begin{array}{l}\text { Most Important aspect is the } \\
\text { verification \&validation }\end{array}$ & $\begin{array}{l}\text { Important aspect is to increase } \\
\text { the formality in the process } \\
\text { Emphasis on tools }\end{array}$ \\
Tool integration & Method integration \\
Pure use of FDTs & Complementary use of FDTs \\
Interest in academic outputs & Interest in internal dissemination \\
Overoptimisic mentality & Overpessimistic mentality \\
Recognition by the scientific & Recognition by top management \\
community & \\
Experimentation know-how & Consolidation practices \\
Emphasis on quality advantage & Emphasis on cost/time savings \\
\hline
\end{tabular}

Figura 9: Inconsistencies between providers and receptors

considered that this is also a way to increase the quality but relying on its merging with current practices.

\section{CONCLUSIONS}

Diffusion of technology cannot be understood without considering the technological frameworks exhibited by all stakeholders involved.

As this paper has analyzed, they could be very different and not shared. The consequence is that the technology perceived by each stakeholder group differs. We have postulated that this is one of the most important causes in order to understand the failures in adopting software technologies.

Several mechanisms were proposed in this paper to address these undesirable effects:

- Analyze the technology transfer profile exhibited by the receptor organization before starting the adoption process. From them, the planning of the adoption process trying to reduce the identified inconsistencies could be done.

- Create circles of diffusion with well defined technological frameworks. In other words, define the technologies perceived by all them. The problem is not that people have different conceptions about the same technology, the problem is that they do not consider it as an input for reducing the problems.

- Share the technological frameworks among all people involved. It does not imply building up a single one; this is not possible. The goal is to be sure that everybody can understand the others before starting the adoption process itself. Interfaces should be clearly stated. At the end of the process, frameworks will be closer. 
- Adapt the transition process to the characteristics of stakeholders by defining reachable goals. Incremental technology transfer models seem appropriate to have time to re-create new technological frameworks when technology is not stable.

- Create observatories to evaluate how the technological frameworks have changed and to propose restructuring of circles of diffusion. This is the basis for being ready for future adoptions.

The experience used as an example demonstrates that technological frames are very important to understand the reasons and problems in accepting a new technology and a basis for reducing those problems even when adoption profiles do not present bad shapes. Nevertheless, much more experience should be collected to be able to extrapolate the results to other scenarios. This will be our future work.

\section{REFERENCES}

1. Akao, J. (1990): Quality Function Deployment. Integrating customer requirements into product design. Productivity Press. Cambridge, Mass.

2. Bergman, L., Ohlund, S.E. (1995): Development of an assessment tool to assist in the implementation of concurrent engineering. CE 95 Conference. Mc Lean Virginia. USA.

3. Fowler, P., Levine, L. (1993): A conceptual framework for software technology transition. Technical Report CMU-SEI-93 TR-31. December 1993.

4. León, G. Carracedo, J., Yelmo, J.C., Sanchez, C., Moreno, J.C., Gil, J.J., Carrasco, F.J. (1994): An industrial experience of using an incremental model of technology transfer of formal development methods. In (Ed. Levine) Diffusion, transfer and implementation of information technology. IFIP Transactions A-45. North-Holland, 1994.

5. Levine, L. (Ed.) (1994): Diffusion, transfer and implementation of information technology. IFIP Transactions A-45. North-Holland, 1994.

6. Linton, L., Hall, D., Hutchinson, K., Hoffman, D., Evanczuk, S., Sullivan, P. (1992): First principles of concurrent engineering. A competitive strategy for product development. CALS/Concurrent Engineering Working Group. Electronic Systems. May 1992.

7. Orlikowski, W.J. and Gash: Technological frame: making sense of information technology in organizations. ACM Transactions on Information Systems. Vol. 12. April 1994. pp 174-207.

8. Saneidian, Kuzaro (1995): SEI capability maturity model's impact on contractors. IEEE Computer. January 1995. Vol. 28. No. 1. pp 16-27. 
9. Shuster, H.D. (1994): The mechanics of cultural change: mobilizing management transformation theory and putting into practice. 2nd International Conference on Integrated Logistics and Concurrent Engineering. Montpellier. Feb. 1994. pp 23-33.

10. Yelmo, J.C., Carrasco, F.J., Sanchez, C., J.J. Gil, Ramos, C., Felipe, M.I. (1994): FDT based development of an interworking unit between LANs and X.25 networks. FORTE'94. Bern (Switzerland). October 1994

\section{BIOGRAPHY}

Prof. Gonzalo León received a phD in Telecommunication Engineering in 1982 from the Technical University of Madrid where he is full professor in the Telematics Department since 1990.

His experience and interest in technology transfer is focused on models for the introduction of immature technologies, basically formal methods, from academia to industrial companies in the telecommunications sector. He is the author of several papers in this field.

He has lectured on technology transfer in graduate courses and he was also responsible for the design of a course on technology transfer in the COMETT programme of the EU. He belongs to the IFIP WG8.6 on Diffusion, Transfer and Adoption of Information Technology where he serves as vice-chairman. 